\title{
ANALISIS FAKTOR-FAKTOR YANG MEMPENGARUHI KESERINGAN MAHASISWA UNHAS MENGIKUTI PROGRAM GUMSB (GERAKAN UNHAS MENGAJI DAN SHOLAT BERJAMAAH) DENGAN MODEL REGRESI LOGISTIK
}

\author{
Suci Barlian Sari ${ }^{1}$, Nurhardianti Mukhtar ${ }^{2}$, Iis Cendrah Kasih ${ }^{3}$, Anisa ${ }^{4}$
}

\begin{abstract}
Abstrak
Mahasiswa merupakan bagian yang memegang peranan penting dalam suatu bangsa. Secara umum mahasiswa menyandang tiga fungsi strategis, yaitu sebagai penyampai kebenaran (agent of social control), sebagai agen perubahan (agent of change), dan sebagai generasi penerus masa depan (iron stock). Namun, pada kenyataannya tidak semua mahasiswa dapat menjalankan fungsinya dengan benar. Masih terdapat banyak mahasiswa yang terlibat kasus kriminal seperti perkelahian, tawuran, pencurian, pembunuhan terhadap dosen, penyalahgunaan narkotika, penipuan, perusakan, dan masih banyak tindakan kriminal lainnya. Berangkat dari kondisi akhlak mahasiswa yang buruk membuat pihak birokrasi unhas prihatin, sehingga pihak birokrasi unhas bekerjasama dengan Asosisasi masjid Kampus Indonesia (AMKI) berinisiatif membuat suatu program "Gerakan Unhas Mengaji dan Sholat Berjamaah (GUMSB)". Tujuan dari penelitian ini adalah untuk mengukur dampak dari GUMSB terhadap minat baca Al-Quran Mahasiswa Unhas dengan model regresi logistik. Analisis pada model regresi logistik digunakan untuk mendeskripsikan hubungan antar variabel terikat yang memiliki dua kategori atau lebih. Variabel terikat pada penelitian ini yaitu keseringan mahasiswa mengikuti GUMSB, dimana kategori yang digunakan pada variabel terikat ini adalah 1 untuk yang sering dan 0 untuk yang jarang mengikuti GUMSB. Sedangkan variabel prediktor yang digunakan adalah semangat dan minat dalam mempelajari Al-Quran dan Organisasi.. hasil dari penelitian ini adalah variable bebas semangat dan minat membaca Al-Quran dan organisasi semuanya mempengaruhi minat baca Al-Quran mahasiswa unhas secara signifikan. Adapun bentuk logit dari model akhir adalah :

$\mathrm{g}^{\wedge}(\mathrm{x})=-5,763+1,229 *$ semangat dan minat dalam mempelajari Al-Quran $+1,004$ *organisasi.
\end{abstract}

Kata Kunci: Mahasiswa; Gerakan unhas Mengaji;Sholat Berjamaah; Al-Quran

1 1,2,3,4 Program Studi Statistika Fakultas Matematika dan Ilmu Pengetahuan Alam, Universitas Hasanuddin

${ }^{1}$ Suciberliansari@gmail.com, ${ }^{2}$ diyanmukhtar@gmail.com

${ }^{3}$ Iiscendrahkasih.91@gmail.com, ${ }^{4}$ nkalondeng@gmail.com 
Suci Barlian Sari, Nurhardianti Mukhtar, Iis Cendrah Kasih, Anisa

\section{PENDAHULUAN}

Mahasiswa merupakan salah satu bagian yang memegang peranan penting dalam suatu bangsa. Secara umum mahasiswa menyandang tiga fungsi strategis, yaitu sebagai penyampai kebenaran (agent of social control), sebagai agen perubahan (agent of change), dan sebagai generasi penerus masa depan (iron stock). Namun, pada kenyataannya tidak semua mahasiswa dapat menjalankan fungsinya dengan benar. Masih terdapat banyak mahasiswa yang terlibat kasus kriminal seperti perkelahian, tawuran, pencurian, pembunuhan terhadap dosen, penyalahgunaan narkotika, penipuan, perusakan, dan masih banyak tindakan kriminal lainnya.

Menurut UU RI No. 20 tahun 2003 tentang Sisdiknas dan UU RI No 14 tahun 2005 tentang Guru dan Dosen, bab I pasal 1 menyatakan "Pendidikan adalah usaha sadar dan terencana untuk mewujudkan suasana belajar dan proses pembelajaran agar siswa secara aktif mengembangkan potensi dirinya untuk memiliki kekuatan spiritual keagamaan, pengendalian diri, kepribadian, kecerdasan, akhlak mulia, serta keterampilan yang diperlukan dirinya, masyarakat, bangsa, dan Negara". Melalui Undang-undang tersebut, sangat jelas bahwa seharusnya pendidikan di Indonesia tidak hanya memperhatikan kecerdasan intelektual saja, melainkan menaruh perhatian lebih pada masalah spiritual juga.

Universitas Hasanuddin (Unhas) merupakan salah satu universitas yang tak luput dalam memperhatikan pengembangan kecerdasan spiritual mahasiswa. Berangkat dari kondisi akhlak mahasiswa yang buruk, pihak birokrasi Unhas berinisiatif membuat sebuah program bertajuk agama, yaitu "Gerakan Unhas Mengaji dan Sholat Berjamaah" untuk mahasiswa yang beragama Islam. Gerakan Unhas Mengaji dan Sholat Berjamaah (GUMSB) merupakan kegiatan yang bertujuan untuk menjadikan mahasiswa dan alumni Unhas sebagai insan cendekia, cendekia lahir dan batin. Sesuai dengan salah satu nilai Unhas, yaitu integritas yang diharapkan mahasiswa dapat tumbuh menjadi generasi jujur, berani, bertanggung jawab, dan teguh dalam pendirian.

GUMSB diharapkan dapat menjadi salah satu solusi untuk mendekatkan mahasiswa kepada Al-Quran. Dengan semakin dekatnya mahasiswa dengan Al-Quran semakin besar pula peluang untuk mengetahui isi kandungan di dalamnya, sehingga dapat membentengi diri mahasiswa untuk berperilaku kriminal. GUMSB harusnya dapat menjadikan mahasiswa layaknya menjadi mahasiswa seharusnya yang merupakan salah satu bagian yang memegang peranan penting dalam suatu bangsa. Serta dapat menjalankan 3 fungsinya dengan benar, yaitu sebagai penyampai kebenaran (agent of social control), sebagai agen perubahan (agent of change), dan sebagai generasi penerus masa depan (iron stock).

Untuk melihat apakah ada pengaruhnya GUMSB dengan minat baca Al-Quran mahasiswa unhas maka di perlukan suatu metode analisis. Regresi Logistik adalah suatu metode analisis statistika untuk mendeskripsikan hubungan antara suatu variabel terikat yang memiliki dua kategori atau lebih dengan satu atau lebih variabel bebas kategori atau interval (Hosmer dan Lemeshow, 2000). Pada prinsipnya, regresi logistik mempunyai tujuan untuk memperkirakan besarnya probabilitas kejadian tertentu di dalam suatu populasi sebagai suatu fungsi eksplanatori. Analisis regresi logistik sering digunakan dalam menganalisis suatu permasalahan dalam kehidupan sehari-hari. Permasalahan yang diangkat dalam penelitian ini adalah Bagaimana pengaruh progam gerakan GUMSB dengan minat baca Alquran Mahasiswa Unhas. Minat baca Alquran Mahasiswa Unhas diteliti melalaui variable semangat dan minat dalam mempelajari Al-Quran (X1) dan pengaruh organisasi (X2). 


\section{TINJAUAN PUSTAKA}

\section{Keutamaan Membaca Alquran}

"Dan kami turunkan dari Al-Quran suatu yang menjadi penawar dan rahmat bagi orang-orang yang beriman dan Al-Quran itu tidaklah menamah kepada orang-orang yang zalim selain kerugian." (QS. Al-Isra:82)

Tentang membaca Al-Quran, Imam Al-Ghazali menuliskan pasal khusus yang berkaitan tentang tilawah Alquran. Pasal ini ditulis karena Al-Quran adalah kitabullah yang disampaikan kepada manusia melalui nabi Muhammad Shallallahu 'alaihi Wasallam untuk dijadikan sebagai pedoman hidup (marja' al-hayah) selama mereka hidup di dunia. Sebagai pedoman hidup, di dalam Al-Quran terdapat norma-norma yang harus dilaksanakan manusia, termasuk soal tata krama membacanya.

Membaca Al-Quran merupakan satu kemuliaan yang diberikan Allah Subhanahu wata'ala kepada umat manusia. Orang Islam yang membaca Al-Quran diumpamakan laksana utrujjah, sejenis jeruk wangi, baunya sedap dan rasanya manis, dan banyak kegunaannya (Syarifuddin, 2004). Dalam rangkaian wahyu Al-Quran yang turun perdana adalah iqra' atau perintah membaca. Iqra terambil dari kata dasar qara'a yang berarti menghimpun, kata iqra juga mempunyai banyak makna antara lain: menyampaikan, menelaah, membaca, mendalami, meneliti, dan mengetahui cirri-cirinya.

\section{Pengantar umum model Regresi Logistik}

Regresi Logistik adalah suatu analisis regresi yang digunakan untuk menggambarkan hubungan antara variabel respon (outcome atau dependent) dengan sekumpulan variabel prediktor (explanatory atau independent), dimana variabel respon bersifat biner atau dikotomus. Variabel dikotomus adalah variabel yang hanya mempunyai dua kemungkinan nilai, misalnya sukses dan gagal. Sedangkan variabel prediktor sering disebut juga dengan covariate. Untuk memudahkan, maka variabel respon diberi notasi Y dan variabel prediktor dinotasikan dengan X. Apabila Y menghasilkan dua kategori, misalnya "1" jika puas dan " 0 " jika tidak puas, maka variabel $\mathrm{Y}$ tersebut mengikuti distribusi Bernoulli, dengan fungsi probabilitasnya adalah :

$\mathrm{f}(\mathrm{yi})=\mathrm{pi}^{\mathrm{yi}}(1-\mathrm{pi})^{1-\mathrm{yi}}, \mathrm{yi}=0,1$

jika yi $=0$ maka $\mathrm{f}(\mathrm{yi})=1-$ pi dan jika yi $=1$ maka $\mathrm{f}(\mathrm{yi})=$ pi

Distribusi dari variabel respon ini merupakan pembeda antara regresi logistik dengan regresi linier. Pada regresi linier variabel responnya diasumsikan berdistribusi normal sedangkan untuk variabel respon pada regresi logistik bersifat dikotomus. Dan fungsi Logistik tersebut adalah sebagai berikut :

$\mathrm{f}(\mathrm{x})=\frac{1}{1+e^{-x}}$

dimana nilai $\mathrm{x}$ berkisar antara $-\infty$ sampai $+\infty$.

Jika $\mathrm{x}=-\infty$, maka $\lim _{x \rightarrow \infty} f(x)=0$

Jika $\mathrm{x}=+\infty$, maka $\lim _{x \rightarrow \infty} f(x)=1$

Dengan melihat kemungkinan nilai $f(x)$ yang berkisar antara 0 dan 1 ini, menunjukkan bahwa regresi logistik sebenarnya menggambarkan probabilitas terjadinya suatu kejadian.

Untuk mempermudah notasi maka digunakan nilai $\pi(\mathrm{x})=\mathrm{E}(\mathrm{Y} \mid \mathrm{X})$ untuk menyatakan rata-rata bersyarat dari $\mathrm{Y}$ jika diberikan nilai $\mathrm{x}$. Bentuk model regresi logistik adalah :

$$
\pi(\mathrm{x})=\frac{\exp \left(\beta_{0}+\beta_{1} x\right)}{1+\exp \left(\beta_{0}+\beta_{1} x\right)}
$$

Pada model regresi linier diasumsikan bahwa pengamatan pada variabel respon dinyatakan sebagai $\mathrm{Y}=\mathrm{E}(\mathrm{Y} \mid \mathrm{X})+\mathrm{e}$, dimana e adalah error yang mengikuti distribusi normal 
dengan mean sama dengan nol dan varians konstan. Sedangkan pada regresi logistik, pola distribusi bersyarat variabel responnya adalah $\mathrm{Y}=\pi(\mathrm{x})+\mathrm{e}$, yang memiliki dua macam nilai error yaitu:

Untuk $\mathrm{y}=1$ maka $\mathrm{e}=1-\pi(\mathrm{x})$, dengan peluang $\pi(\mathrm{x})$

Untuk $\mathrm{y}=0$ maka $\mathrm{e}=-\pi(\mathrm{x})$, dengan peluang $1-\pi(\mathrm{x})$

Sehingga distribusi errornya mempunyai mean sama dengan nol dan varians $\{\pi(x)(1-$ $\pi(x)\}$, yang mengikuti distribusi binomial.

\section{Estimasi Parameter}

Dalam regresi linier, metode yang sering digunakan untuk menaksir parameter yang belum diketahui adalah dengan metode Least Square. Dengan metode ini dapat ditentukan nilai $\beta_{0}$ dan $\beta_{1}$ yang meminimumkan jumlah kuadrat deviasi (error) nilai observasi Y dari nilai dugaannya. Tetapi cara least square ini tidak dapat diterapkan pada model dengan variabel respon yang dikotomus. Nilai taksiran parameternya akan berbeda dengan nilai taksiran yang didapat dari regresi linier. Penaksiran parameter pada regresi logistik mengunakan cara lain, yaitu Maximum Likelihood. Metode ini merupakan dasar pendekatan dalam menaksir parameter pada model regresi logistik. Pada dasarnya metode maximum likelihood memberikan nilai taksiran parameter dengan memaksimalkan fungsi likelihood. Jika Y dikodekan 0 dan 1, maka $\pi(x)$ pada persamaan (2.3) menyatakan probabilitas bersyarat untuk $\mathrm{Y}$ sama dengan 1 jika diberikan nilai $\mathrm{x}$. Hal ini dapat dinyatakan sebagai $\mathrm{P}(\mathrm{Y}=1 \mid \mathrm{x})$. Demikian juga untuk $1-\pi(\mathrm{x})$ menyatakan probabilitas bersyarat untuk $\mathrm{Y}$ sama dengan nol jika diberikan nilai $x$, yaitu $P(Y=0 \mid x)$. Sehingga untuk pasangan (xi,yi) dimana $y 1=1$ kontribusi pada fungsi likelihoodnya adalah $\pi(\mathrm{xi})$ dan untuk yi $=0$ kontribusi pada fungsi likelihoodnya adalah 1$\pi(\mathrm{xi})$, dimana $\pi(\mathrm{xi})$ menyatakan nilai $\pi(\mathrm{x})$ yang dihitung pada xi .

\section{Pengujian Estimasi Parameter}

Setelah menaksir parameter maka langkah selanjutnya yang dilakukan terhadap model adalah menguji signifikansi dari variabel yang ada dalam model. Untuk itu digunakan uji dan hipotesis statistik untuk menentukan apakah variabel prediktor dalam model signifikan atau berpengaruh secara nyata terhadap variabel respon. Pengujian signifikansi parameter dilakukan sebagai berikut :

\section{a. Uji parsial}

Dalam uji parsial ini, pengujian dilakukan dengan menguji setiap $\beta$ i secara individual. Hasil pengujian secara individual akan menunjukkan apakah suatu variabel prediktor layak untuk masuk dalam model atau tidak.

Hipotesis :

Ho : $\beta \mathrm{i}=0 \mathrm{i}=1,2,3, \ldots, \mathrm{k}$

$\mathrm{H} 1: \beta \mathrm{i} \neq 0$

Statistik uji yang digunakan adalah Uji Wald, yaitu :

$$
W_{i}=\frac{\beta_{i}}{S E\left(\beta_{i}\right)}
$$

Statistik uji Wald ini mengikuti distribusi normal, sehingga untuk memperoleh keputusan pengujian dibandingkan dengan distribusi normal (Z). Kriteria penolakan (tolak Ho) jika nilai $\mathrm{W}$ lebih besar dari $z_{\propto / 2}$

\section{b. Uji serentak}

Uji serentak disebut juga dengan uji Model Chi-Square yaitu digunakan untuk menguji parameter hasil dugaan secara bersama-sama atau dengan kata lain untuk memeriksa keberartian koefisien $\beta$ secara keseluruhan atau serentak.

Dan hipotesa pengujiannya adalah :

Ho : $\beta \mathrm{o}=\beta 1=\ldots=\beta \mathrm{k}$

H1 : Paling sedikit ada satu $\beta \mathrm{k}$ yang tidak sama dengan nol. 
Adapun statistik uji yang dilakukan adalah statistik uji $\mathrm{G}$ atau Likelihood Ratio Test, yaitu :

$$
G=-2 \operatorname{Ln} \frac{\left[\frac{n_{1}}{n}\right]^{n_{1}}\left[\frac{n_{0}}{n}\right]^{n_{2}}}{\sum_{i=1}^{n}\left[\widehat{\pi}_{i}\right]^{y_{i}}\left[1-\widehat{\pi}_{i}\right]^{1-y_{i}}}
$$

Dimana : $n_{0}=\sum_{i=1}^{j}(1-y) ; n_{i}=\sum_{i=1}^{j} y_{i}$ dan $n=n_{0}+n_{1}$

Statistik uji $\mathrm{G}$ ini mengikuti distribusi Chi-Square $(\chi 2)$ dengan derajat bebas $\mathrm{v}$ (banyaknya parameter dalam model), karena itu untuk memperoleh keputusan pengujian nilai $\mathrm{G}$ ini dibandingkan dengan nilai $\chi 2 \alpha$,v. kriteria penolakan (tolak Ho) jika nilai G lebih besar dari $\chi 2 \alpha, \mathrm{v}$.

\section{METODOLOGI PENELITIAN}

\subsection{Waktu dan tempat}

Penelitian dilakukan pada bulan April 2018. Tempat penelitian berupa pengambilan data kuesioner dilaksanakan di Masid Kampus Unhas.

\subsection{Populasi dan sampel}

Populasinya adalah mahasiswa Unhas dan jumlah sampel yang akan digunakan dalam penelitian ini yaitu sebanyak 70 responden.

\subsection{Teknik Pengambilan Sampel}

Teknik pengambilan sampel yang digunakan dalam penelitian ini adalah Stratified sampling yaitu teknik pengambilan sampel dengan membagi antara sampel yang berjenis kelamin laki-laki dan perempuan.

\subsection{Sumber data}

Data yang digunakan dalam penelitian ini merupakan data primer yang diperoleh dari hasil survey pengaruh GUMSB terhadap minat baca Al-Quran Mahasiswa Unhas. GUMSB di teliti melalui variable semangat dan minat dalam mempelajari Al-Quran (X1), pengaruh organisasi dalam membaca Al-Quran (X2).

\subsection{Identifikasi Variabel}

Variabel-variabel yang digunakan dalam penelitian ini adalah:

1. Variabel Respon (Y) adalah keseringan mahasiswa mengikuti GUMSB dengan kategori:

$$
\begin{aligned}
& 1=\text { sering } \\
& 0=\text { jarang }
\end{aligned}
$$

2. Variabel-variabel yang diduga mempengaruhikeseringan mahasiswa GUMSB yaitu:

a. Minat baca Al-Quran Mahasiswa (X1)

b. Pengaruh organisasi dalam membaca Al-Quran (X2)

\subsection{Langkah-langkah Penelitian}

Metode yang digunakan pada penelitian ini adalah pemodelan yaitu dengan menerapkan teori model regresi logistik beserta uji kecocokannya untuk menganalisis data. berikut.

Langkah - langkah yang ditempuh untuk mencapai tujuan penelitian ini sebagai

1. Pengambilan sampel dilakukan sebagi berikut.

a. Menentukan variabel-variabel yang akan diteliti.

b. Menentukan teknik sampling, ukuran sampling dan unit-unit sampling.

c. Merancang kuesioner.Melakukan survey dan mengumpulkan data primer tentang kondisi sosial mahasiswa 
2. Menerapkan model regresi logistik pada data sampel yang diperoleh, yaitu menaksir parameter model dengan metode maksimum likelihood, menguji signifikansi parameter yang diperoleh dari hasil penaksiran, dan menerapkan uji kecocokan model regresi logistik dengan uji Hosmer dan Lemeshow.

3. Membuat kesimpulan dan interpretasi dengan rasio odds dari model yang sudah diuji kecocokannya.

\section{ANALISIS DATA DAN PEMBAHASAN}

\subsection{Uji Validitas dan Reliabilitas}

\subsubsection{Uji Validitas}

Uji validitas ini hanya dilakukan pada variabel-variabel yang dianggap mempengaruhi GUMSB terhadap minat baca Al-Quran Mahasiswa Unhas. Dengan hasil uji validitas sebagai berikut:

Tabel 4.1 Nilai total Koreksi korelasi

\begin{tabular}{|c|c|}
\hline \multicolumn{1}{|c|}{ Variabel } & Total Koreksi korelasi \\
\hline $\begin{array}{l}\text { Semangat dan Minat membaca Al- } \\
\text { Quran }\end{array}$ & 0,547 \\
\hline Organisasi & 0,621 \\
\hline
\end{tabular}

Hipotesis yang digunakan untuk masing-masing pertanyaan adalah :

Ho : Pertanyaan tidak mengukur aspek yang sama

$\mathrm{H} 1$ : pertanyaan mengukur aspek yang sama

Jika dibandingkan maka angka-angka total koreksi korelasi yang diperoleh dengan angka kritik pada tabel korelasi $\mathrm{r}$ (produk moment) dengan $\alpha=0,05$ dan $\mathrm{n}=70$ dengan derajat bebas sebesar $70-2=68$, diperoleh angka kritik sebesar 0,284. Karena total koreksi korelasi yang diperoleh dari masing-masing pertanyaan yang terdapat dalam Tabel 4.1 berada diatas nilai kritik dengan taraf 5\% maka semua pertanyaan tersebut mengukur aspek yang sama dan dapat digunakan untuk mencari pola hubungan selanjutnya.

\subsubsection{Uji Reliabilitas}

Untuk menguji apakah pertanyaan-pertanyaan tersebut konsisten, maka dilakukan pengujian reliabilitas. Dengan hipotesis sebagai berikut :

Ho : Hasil pengukuran tidak konsisten

H1 : Hasil pengukuran konsisten

Berdasarkan output pada reliabiliti analisis pada Lampiran maka diperoleh nilai alpha sebesar 0,853 . Ternyata nilai alpha yang diperoleh berada diatas nilai kritik $(0,6)$, sehingga dapat dikatakan skala pengukur yang disusun adalah reliabel dan hasil pengukuran masing-masing pertanyaan konsisten.

4.2 Faktor-faktor yang Berpengaruh Terhadap minat baca Al-Quran Mahasiswa Unhas

Untuk mengetahui faktor-faktor yang berpengaruh terhadap minat baca Al-Quran Mahasiswa Unhas, maka dilakukan analisis regresi logistik baik secara univariate maupun multiple.

Analisis regresi logistik univariate (individu) digunakan untuk mengetahui pengaruh dari masing-masing variabel prediktor terhadap minat baca Al-Quran 
Suci Barlian Sari, Nurhardianti Mukhtar, Iis Cendrah Kasih, Anisa

mahasiswa unhas secara individu. Caranya adalah dengan membuat regresi logistik untuk masing-masing variabel prediktor terhadap minat baca Al-Quran mahasiswa unhas. Hasil dari analisis regresi logistik univariate adalah sebagai berikut :

\section{a. Pengaruh Semangat dan minat dalam mempelajari Al-Quran}

Untuk mengetahui apakah variabel Semangat dan minat dalam mempelajari AlQuran berpengaruh terhadap minat baca Al-Quran mahasiswa unhas maka dilakukan uji parsial dengan hipotesis :

Ho : $\beta=0$, artinya Pengaruh Semangat dan minat dalam mempelajari Al-Quran tidak berpengaruh terhadap minat baca Al-Quran mahasiswa unhas

$\mathrm{H} 1: \beta \neq 0$, artinya semangat dan minat dalam mempelajari Al-Quran berpengaruh terhadap minat baca Al-Quran mahasiswa unhas

Hasil dari analisis regresi logistik antara variabel semangat dan minat dalam mempelajari Al-Quran itu sendiri dengan minat baca Al-Quran mahasiswa unhas pada Tabel 4.2 .

Tabel 4.2 Hasil regresi logistik antara semangat dan minat dalam mempelajari Al-Quran dengan minat baca Al-Quran mahasiswa unhas

\begin{tabular}{|c|c|c|c|c|c|}
\hline variabel & B & SE & Wald & Df & Sig. \\
\hline $\begin{array}{c}\text { semangat } \\
\text { dan minat } \\
\text { dalam } \\
\text { mempelajari } \\
\text { Al-Quran }\end{array}$ & 1,189 & 0,538 & 4,896 & 1 & 0,27 \\
\hline konstan & $-2,447$ & 1,742 & 1,973 & 1 & 0,160 \\
\hline
\end{tabular}

Dari Tabel 4.2 didapatkan nilai uji Wald sebesar 4,896 yang lebih besar dari $=$ 3,841 sehingga tolak Ho, yang berarti bahwa faktor semangat dan minat dalam mempelajari Al-Quran itu sendiri memiliki pengaruh terhadap minat baca Al-Quran mahasiswa unhas .

\section{b. Pengaruh organisasi terhadap minat baca Al-Quran mahasiswa Unhas}

Untuk mengetahui apakah variabel organisasi berpengaruh terhadap minat baca Al-Quran mahasiswa unhas maka dilakukan uji parsial dengan hipotesis:

$\mathrm{H}_{0}: \beta=0$, artinya variabel organsisasi tidak berpengaruh terhadap minat baca Al-Quran mahasiswa Unhas

$\mathrm{H}_{1}: \beta \neq 0$, artinya variabel organsisasi berpengaruh terhadap minat baca Al-Quran mahasiswa Unhas

Hasil dari analisis regresi logistik antara variabel organisasi dengan minat baca Al-Quran mahasiswa Unhas dapat dilihat pada Tabel 4.3 berikut.

Tabel 4.3 Hasil regresi logistik antara variabel organisasi dengan minat baca Al-Quran mahasiswa.

\begin{tabular}{|l|c|c|c|c|c|}
\hline variabel & B & SE & Wald & Df & Sig. \\
\hline $\mathrm{D}_{\text {organisasi }}$ & 0,981 & 0,444 & 4,877 & 1 & 0,27 \\
\hline $\mathrm{D}$ konstan & $-1,670$ & 1,418 & 1,389 & 1 & 0,239 \\
\hline
\end{tabular}


Suci Barlian Sari, Nurhardianti Mukhtar, Iis Cendrah Kasih, Anisa

Dari Tabel 4.3 didapatkan nilai uji Wald sebesar 4,877 yang lebih besar dari $=3,841$ sehingga tolak Ho, yang berarti bahwa variabel organisasi memiliki pengaruh yang besar terhadap minat baca Al-Quran mahasiswa unhas.

Setelah dilakukan analisis regresi logistik secara univariate terhadap semua variabel prediktor, maka langkah selanjutnya adalah melakukan analisis regresi logistik secara multiple dengan memasukkan semua variabel prediktor.

Analisis regresi logistik multiple (bersama) digunakan untuk menentukan variabel prediktor yang berpengaruh terhadap minat baca Al-Quran mahasiswa unhas secara bersama-sama. Caranya adalah dengan membuat regresi logistik yang memasukkan semua variabel prediktor. Metode yang digunakan untuk menyeleksi model dalam penelitian ini adalah metode Forward yaitu memasukkan satu persatu variabel prediktor yang berpengaruh (signifikan).

Langkah-langkah pembentukan model dengan menggunakan metode Forward adalah sebagai berikut:

Tahap 1

Pada tahapan pertama ini, variabel prediktor yang masuk terlebih dahulu adalah variabel semangat dan minat dalam mempelajari Al-Quran Hal ini bisa dilihat dari nilai score yang paling besar dibandingkan variabel yang lain. Ketika di uji secara parsial, nilai Wald dari variabel empati sebesar 4,896, dimana nilai ini lebih besar daripada nilai $\mathrm{x}_{0,05 ; 1}^{2}=3,841$, sehingga tolak $\mathrm{H}_{0}$ yang artinya bahwa variabel semangat dan minat dalam mempelajari Al-Quran berpengaruh dengan minat baca Al-Quran mahasiswa unhas

Tahap 2

Pada tahapan kedua, variabel yang masuk berikutnya adalah variabel yang nilai score dari variabel yang lebih kecil nilai score dari variabel lain. Jika di uji secara parsial, maka variabel ini memiliki nilai Wald yang kecil.

Jadi model terakhir yang didapatkan setelah variabel yang tidak berpengaruh terhadap minat baca Al-Quran mahasiswa unhas tidak diikutkan dalam model adalah sebagai berikut:

Tabel 4.4 Model akhir regresi logistik multiple minat baca Al-Quran mahasiswa unhas

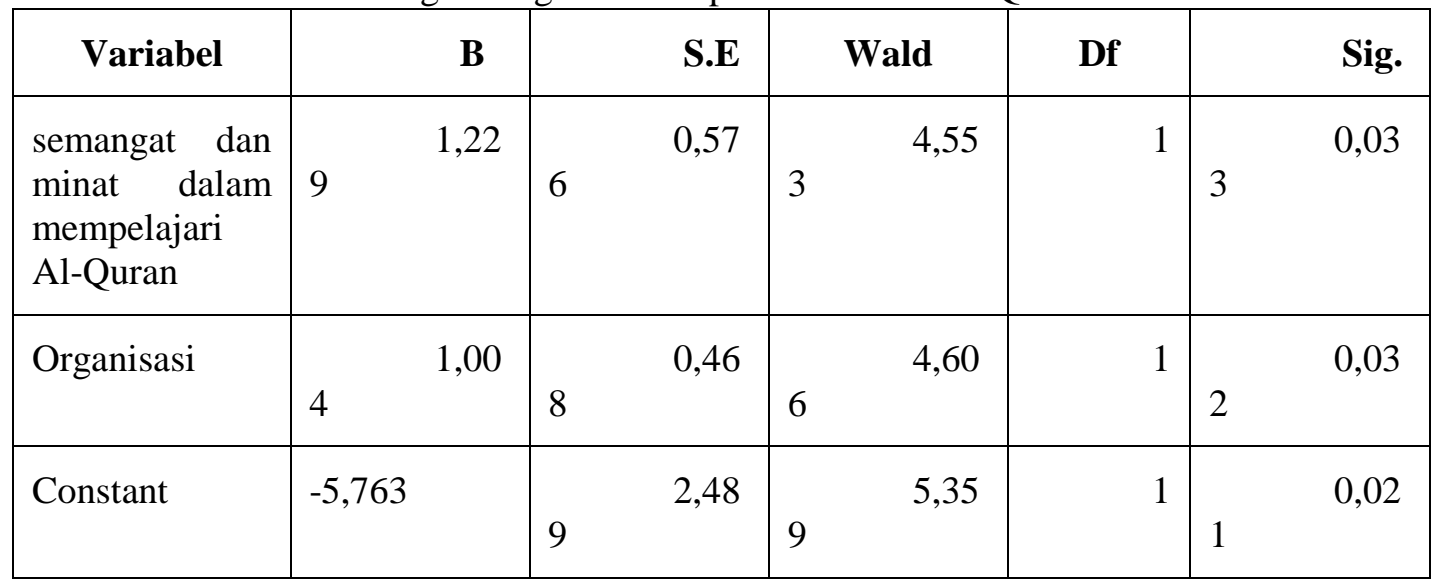

Dari tabel 4.4 sehingga didapatkan model logit dari model terakhir ini adalah sebagai berikut :

$$
g^{\wedge}(x)=-5,763+1,229 * \text { semangat dan minat dalam mempelajari Al-Quran }+
$$

$1,004 *$ organisasi 


\section{Suci Barlian Sari, Nurhardianti Mukhtar, Iis Cendrah Kasih, Anisa}

Dari model akhir ini didapatkan bahwa semua variabel berpengaruh terhadap minat baca Al-Quran mahasiswa unhas.

\subsection{Uji Kesesuaian Model}

Uji kesesuaian model dilakukan untuk menguji apakah model sudah sesuai, dalam artian tidak ada perbedaan antara hasil observasi dengan kemungkinan hasilprediksi model. Hasil uji kesesuaian model pada data faktor-faktor yang mempengaruhi minat baca Al-Quran mahasiswa unhas adalah sebagai berikut.

Hipotesis :

H0 : Model sesuai (tidak terdapat perbedaan yang signifikan antara hasil pengamatan dengan kemungkinan hasil prediksi model)

H1 : Model tidak sesuai (terdapat perbedaan yang signifikan antara hasil pengamatan dengan kemungkinan hasil prediksi model)

Taraf signifikan: $\alpha=0,05$

Daerah kritis: Tolak H0 jika P_value $<\alpha$

Tabel 4.5 Hasil uji kesesuaian model

\begin{tabular}{|l|c|c|c|}
\hline & Chi- Kuadrat & Df & Sig. \\
\hline Hosmer and Lemeshow Test & 7,107 & 3 & 0,069 \\
\hline
\end{tabular}

Tabel 4.5 menunjukkan bahwa dengan derajat bebas sebesar 3, didapatkan nilai chi-kuadrat untuk uji kesesuaian model sebesar 7,107. Dengan P-value sebesar 0,069 dapat diambil keputusan gagal tolak $\mathrm{H}_{0}$ karena $0,069>\alpha(0,05)$ sehingga dapat ditarik kesimpulan bahwa model sesuai. Hal itu berarti tidak terdapat perbedaan yang signifikan antara hasil pengamatan dengan kemungkinan hasil prediksi model.

\subsection{Ketepatan Klasifikasi Model}

Dari hasil regresi multiple terdapat tabel klasifikasi untuk minat baca Al-Quran mahasiswa unhas. Tabel ini menggambarkan seberapa tepat model yang diperoleh dapat memprediksi variabel respon (Keseringan mengikuti GUMSB) dan dapat pula dilihat pada Tabel 4.6.

Tabel 4.6. memprediksi variabel respon (Keseringan mengikuti GUMSB)

\begin{tabular}{|l|l|l|l|l|}
\hline \multicolumn{2}{|c|}{} & \multicolumn{2}{|c|}{ Prediksi } & \multirow{2}{*}{ Percent correct } \\
\cline { 3 - 5 } \multicolumn{2}{|c|}{} & jarang & sering & \\
\hline \multirow{2}{*}{ Observed } & jarang & 4 & 9 & $30,8 \%$ \\
\cline { 2 - 5 } & sering & 1 & 56 & $98,2 \%$ \\
\hline & & & overall & $85,7 \%$ \\
\hline
\end{tabular}

Dari Tabel 4.6 terlihat bahwa, dari 5 responden yang jarang mengikuti GUMSB, 4 responden diprediksi dengan benar oleh model. Dan dari 65 responden yang sering mengikuti GUMSB, ada sebanyak 56 responden yang diprediksi dengan benar oleh model. Untuk kolom yang lain adalah kesalahan klasifikasi, sehingga secara keseluruhan ada sebesar 60 dari 70 responden dapat diprediksi dengan tepat oleh model yaitu sebesar $85,7 \%$.

\subsection{Interpretasi Koefisien Parameter}

Setelah didapatkan model terbaik maka langkah selanjutnya adalah melakukan interpretasi dari koefisien parameter. Untuk model regresi logistik dengan variabel prediktor yang berskala kategori, maka odds rasionya dinyatakan dengan $\psi=e^{\beta}$. Nilai 
Suci Barlian Sari, Nurhardianti Mukhtar, Iis Cendrah Kasih, Anisa

odds ratio untuk masing-masing variabel prediktor pada model akhir dapat dilihat pada Tabel 4.7.

Tabel 4. 7 Odds ratio untuk model akhir

\begin{tabular}{|c|c|c|}
\hline ariabel & B & $\operatorname{Exp}(B)$ \\
\hline $\begin{array}{l}\text { semangat dan minat } \\
\text { dalam mempelajari Al- } \\
\text { Quran }\end{array}$ & 1,229 & 3,418 \\
\hline organisasi & 1,004 & 2,728 \\
\hline
\end{tabular}

Interpretasi dari odds ratio untuk masing- masing variabel prediktor adalah :

a. semangat dan minat dalam mempelajari Al-Quran

Jika faktor semangat dan minat dalam mempelajari Al-Quran adalah konstan, maka odds mahasiswa yang sering mengikuti GUMSB akan naik sebesar 3,418 kali dari mahasiswa yang jarang mengikuti GUMSB.

b. Variabel organisasi

Jika faktor organisasi dianggap konstan, maka odds mahasiswa yang sering mengikuti GUMSB akan 2,728 kali dari mahasiswa yang jarang mengikuti GUMSB.

\section{KESIMPULAN DAN SARAN}

\subsection{Kesimpulan}

Setelah dilakukan pengumpulan data, pengolahan dan analisis maka kesimpulan yang diperoleh dengan analisis regresi logistik adalah variable bebas semangat dan minat membaca Al-Quran dan organisasi semuanya mempengaruhi minat baca Al-Quran mahasiswa unhas secara signifikan. Adapun bentuk logit dari model akhir adalah :

$g^{\wedge}(x)=-5,763+1,229 *$ semangat dan minat dalam mempelajari Al-Quran + $1,004 *$ organisasi

\subsection{Saran}

Saran yang diberikan oleh mahasiswa kepada pihak birokrasi unhas maupun panitia GUMSB yaitu menggencarkan publikasi kegiatan sebelum GUMSB berlangsung karena ada sebagian mahasiswa yang kurang mengetahui kegiatas $\backslash n$ tersebut. Selain itu program GUMSB ini akan lebih efektif jika di lakukan follow-up seperti pembentukan halaqoh tahsin dan sebagainya agar dapat memperbaiki tajwid dalam Al-Quran.

\section{DAFTAR PUSTAKA}

Agresti, Alan. (1990), Categorical Data Analysis, John Wiley and Sons, Inc, New York.

Hosmer DW, Lemeshow S. 2000. Applied Logistic Regression 2nd Edition. New

York: John Wiley \& Sons, Inc.

Syarifuddin, Ahmad..2004.Mendidik Anak Membaca, Menulis dan Mencintai AlQuran. Jakarta:PT Gema Insani. 